\title{
Scaling of spatial variation in ground flora of Tharparker, Pakistan
}

\author{
Sheikh Saeed Ahmad' ${ }^{1}$. Daniel Potter ${ }^{2}$
}

Received: 16 June 2020 / Accepted: 17 September 2020 / Published online: 29 September 2020

(c) Springer Nature Switzerland AG 2020

\begin{abstract}
The role of vegetation is very important in ecosystem conservation. The present study was conducted to classify the existing ground flora in Tharparker, Pakistan. The distribution pattern of vegetation and species association was grouped into different communities by using ordination techniques. Both direct and indirect ordination methods were applied to classify the species into groups and communities, and also quantify the relationship of species with varied soil parameters $\left(\mathrm{pH}, \mathrm{EC}\right.$, moisture, $\left.\mathrm{OM}, \mathrm{K}, \mathrm{P}, \mathrm{Fe}^{+3}, \mathrm{Zn}^{+2}, \mathrm{Mn}^{+2}, \mathrm{Cu}^{+2}\right)$. Plant and soil samples were randomly collected using quadrat of $1 * 1 \mathrm{~m}^{2}$. Two main groups and four communities were formed by species derived from fifty quadrat. Cynodon dactylon and Desmostachya bipinnata showed higher abundance over the broad range of all edaphic factor's concentration. This study provided the significant results of least abundant and most abundant herbaceous species in the region of Tharparker, which will be helpful for land managing and planning.
\end{abstract}

Keywords Ecological model $\cdot$ Herbaceous plants $\cdot$ Multivariate $\cdot$ Ordinal classification

\section{Introduction}

In ecology, plant distribution and relationship of plant species with environmental gradient is significantly important, because it reflects the pattern of species abundance and diversity [1]. Studying the relationship of species with environmental parameter and classification not only is important in the research field of ecology, but also gets difficult for analyzing the community structure. Complexity of interaction between plants and abiotic factors is a major constraint for predicting plant response to environmental changes. However, vegetation response and future scenario can be predicted by computer models. Computer simulation is dependant on accurate data set of parameters and not limited by time and space which is hurdle in experimentation. In the case of conservation and management practices, classification is very important which depends upon the scale of measurement. In this perspective, multivariate techniques are very useful in ecology [2]. For the identification of association within species on the basis of abundance and vegetation composition, two-way indicator species analysis (TWINSPAN) technique is widely applied by ecologist.

Existence and abundance of different plant species depend upon the spatial variability within the area. Plants show different growth responses to spatially distributed edphaic factors like the presence of moisture, macronutrients and micronutrients.

Many researches have shown the importance of direct and indirect ordination techniques of multivariate. Likewise, the relationship between environmental parameter and plant species along distribution pattern in Chott El Beida (RAMSAR protect wetland) situated in Algeria was studied using TWINSPAN, and 127 species of 41 families were identified within four communities [3]. This study improved the baseline record of vegetation community. In Pakistan, different studies based on ordination techniques have been carried out. Likewise, Khan et al. [4] studied the vegetation and distribution pattern in semiarid area of Pakistan using ordination techniques.

Sheikh Saeed Ahmad, drsaeed@fjwu.edu.pk| 'Department of Environmental Sciences, Fatima Jinnah Women University, Rawalpindi, Pakistan. ${ }^{2}$ Department of Plant Sciences, University of California, Davis, USA. 
Urooj et al. [5] investigated the relationship between the plant growth and environmental parameters and showed the generalized linear model of species growth response at a varied range of physical and chemical parameters. Using these techniques, distribution pattern, abundance, types of species and influence of physical environmental factors on species can be studied and investigated. In another study, vegetation of 40 quadrats was classified into communities using TWINSPAN [6].

In the present study, an effort has been made to analyze and explore the correlation of plant communities with edphaic factors. Desert is extremely dry areas supporting sparse distinctive vegetation including mostly shrubs and herbs specially adapted to the harsh environment.

The objectives of the present study were to classify the existing herbaceous flora of the ecologically important arid region (Tharparker) during wet season and to analyze the effect of soil parameters on the growth of herbaceous flora using ordination technique.

\section{Materials and methods}

\subsection{Study area}

Tharparker is located between $24.159^{\circ}$ and $25.7^{\circ} \mathrm{N}$ latitude and $69.059^{\circ}$ and $71.2426^{\circ} \mathrm{E}$ longitude and is the largest district land area of Sindh province. Land is mostly deserted and consists of rainfed vegetation. Rainfall only occurs in the months of June, July and August [7]. Land of Tharparker depicted a classic green view during the period of sufficient rainfall, like in the period of monsoon. Tharparker district has tropical desert climate which is hot during the summer and coldest in winter. However, annual rainfall is recorded as low as $100 \mathrm{~mm}$ which fluctuated more often and maximum precipitation is recorded during the monsoon season. Saand et al. [7] reported dominant vegetation in Tharparker belongs to Poaceae and Fabaceae families. About $60 \%$ species are herbaceous, and $40 \%$ are reported as shrub. Mostly trees and shrubs are on farmland and come under the property right of inhabitant, and the only prohibited thing is that nobody is allowed to cut any tree from farmland, but herbs and grasses that grow on rangeland are more prone to threat [7]. The community structure and plant distribution pattern of Tharparker region are poorly understood and have not been given by plant ecologist till the date.

\subsection{Data and methodology}

During growing season (July-September), plants were collected along with soil samples using $1 \times 1 \mathrm{~m}^{2}$ quadrat in the year 2018. Total 50 quadrats were laid down, and Domin cover scale was used to estimate the cover value of each species from each quadrat [5]. Soil samples were randomly collected along vegetation from each quadrat at depth of $6-12 \mathrm{~cm}$. Vegetation classification was carried out using the technique of TWINSPAN via software PCORD which indicated the abundance of each species in each quadrat. DCA was applied as another indirect ordination technique for the verification of TWINSPAN results [8-12]. Moreover, dominance curve was also created between log values of sum abundance and rank of abundance which described the ranks of species on their abundance/frequency of the existence in the study area. For the assessment of the relationship between species and available soil parameters, a direct ordination technique named CCA was applied using the Canoco 4.5 version [13]. Soil parameters included pH, EC, organic matter, potassium, phosphorous, moisture, zinc, copper, ferrous and manganese. Soil samples were analyzed for soil $\mathrm{pH}$ and EC by preparing soil extract solution in 1:2 ratio [14], and soil organic matter was calculated by following the procedure of Nathan and Gelderman [15]. Samples were dried, pulverized and sieved by using 2-mmsize sieve for all chemical analyses except soil moisture and organic matter. Method of Nathan and Gelderman [15] was followed for analyzing macronutrients ( $\mathrm{P}$ and $\mathrm{K}$ ) which are essential for plant growth. Method of acid digestion using aqua regia (containing 3:1 ratio of $\mathrm{HCl}$ and $\mathrm{HNO}_{3}$ ) given by Ehi-Eromosel et al. [16] was applied for analyzing the micronutrients on atomic absorption spectrophotometer. Generalized additive model (GAM) as modern regression method was applied to provide the correct interpretation of ordination [17]. Species response model-based ordination is the best to interpret the change of species response along the ordination axes. In the present study, generalized additive model (GAM) was applied based on the following equation of linear model [18].

$Y=E Y+e$

And $E Y=f(X 1, \ldots, X p)$

where $Y$ is the response variable, $E Y$ is the response variable expected for predictor and $e$ is the variability of true value around the expected value $E Y . X 1-X p$ are predictor values. In Eq. (1), $E Y$ is the systematic component, and $e$ is the stochastic component of regression model.

However, GAM extends the general linear model in two ways: Firstly, $E Y$ is not supposed to be always directly equal to the linear combination of the $X 1-X p$. Instead, scale of predictor determines the scale of response variables using parametric function known as link function given in Eq. 3; secondly, GLM has less specific assumptions about the stochastic component as compared to the general linear models [19]. 
$g(E Y)=\eta$

$\eta=\beta 0+\beta j X j$

where $\eta$ is the linear predictor.

\subsection{Results and discussion}

In total, 21 species were identified that belong to 6 families. Species were classified using TWINSPAN technique, which divides the percentage cover scale into six groups using five cut levels. This indicated the occurrence of species in particular quadrats. The hierarchy of classified species is shown by species dendogram in Fig. 1, which represents two main groups $A$ and $B$. Group $A$ indicated only one species, i.e., Cynodon dactylon (Poaceae), whereas Group B was divided into four communities presented with different colors, showing community of associated species against similar habitat conditions in the area.

Community I under the group B comprised of eight species, i.e., Ochthochloa compressa (Poaceae), Cenchrus setigerus (Gramineae), Panicum antidotale (Poaceae), Dichanthium annulatum (Poaceae), Sporobolus marginatus (Poaceae), Typha species (Typhaceae), Orghum halepense (Poaceae) and Tribulus terrestris (Zygophyllaceae). On the basis of dominant species (Typha species, Sorghum halepense), this community was given a name Typ-Sor. Similarly, community II was named as Cit-Phr due to the Phragmites species (Poaceae), the Citrullus colocynthis (Cucurbitaceae) being the dominant species. Besides, total four species were enlisted in community II. Panicum turgidum (Poaceae) and Saccharum spontaneum (Poaceae) were the other than two dominant species in this community. Cenchrus ciliaris (Poaceae) and Lasiurus scindicus (Poaceae) were the dominant species in the community III and named as Las-Cen. This community also comprised Cenchrus biflorus (Poaceae) species. The community IV was

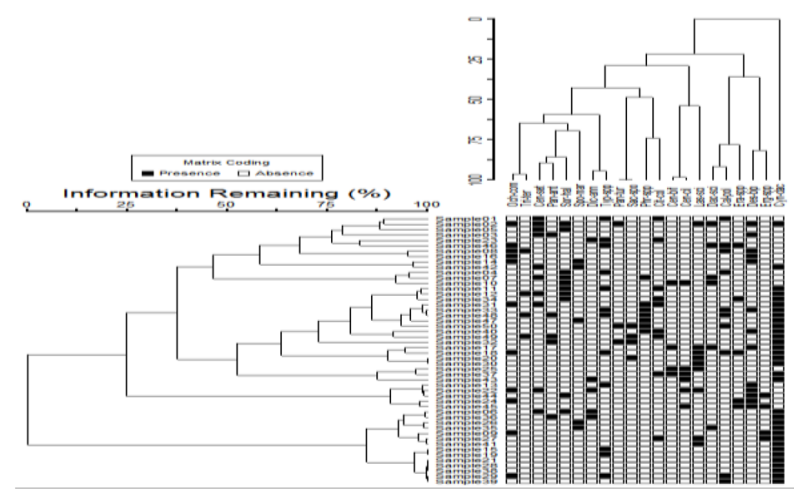

classified on the basis of five species and named as Des-Cal on the abundance of Desmostachya bipinnata (Poaceae) and Calligonum polygonoides (Polgonaceae) species along the other three more species, i.e., Eragrostis species (Poaceae), Ergamopagan species and Dactyloctenium scindicum (Poaceae).

Figure 2 shows the curve between the log sum and rank abundance which indicated the abundance of each species at unit time in the study area. This presented the status of $C$. dactylon as the most frequent species and placed this in the first rank in the curve. D. bipinnata showed the second and S. halepense was placed in the third rank followed by $C$. dactylon. Two species T. terrestris and P. turgidum were present at the lower rank due to the lesser abundance shown by the log value of sum abundance, i.e., 0.698.

Results of TWINSPAN were verified and supported with another ordination technique named as detrended correspondence analysis (DCA) shown in Fig. 3.

Results of DCA presented community of Ochthochloa Compressa, Panicum antidotale, Tribulus terrestris and Dichanthium annulatum, Typha species, shown in

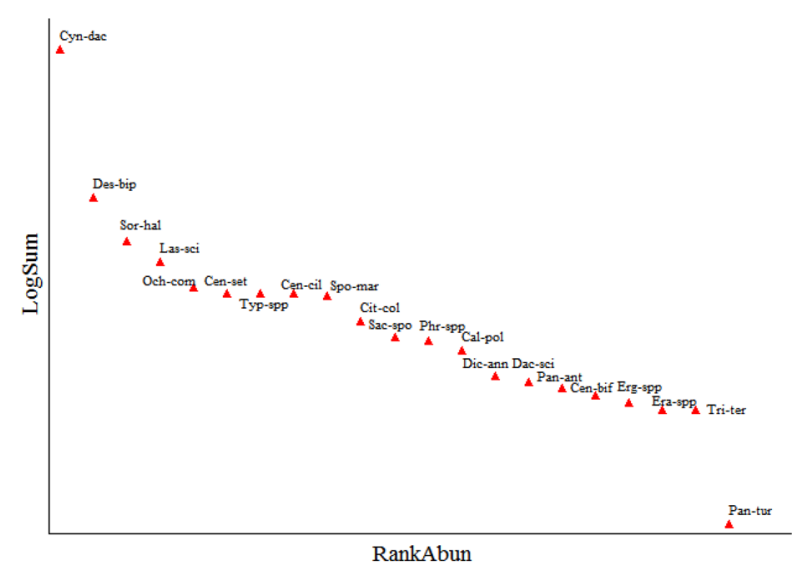

Fig. 2 Dominance curve

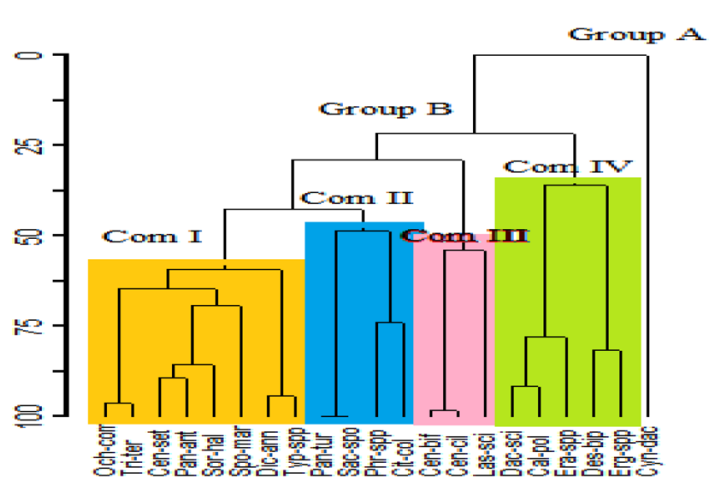

Fig. 1 Two-way cluster analysis of Tharparker plant species 


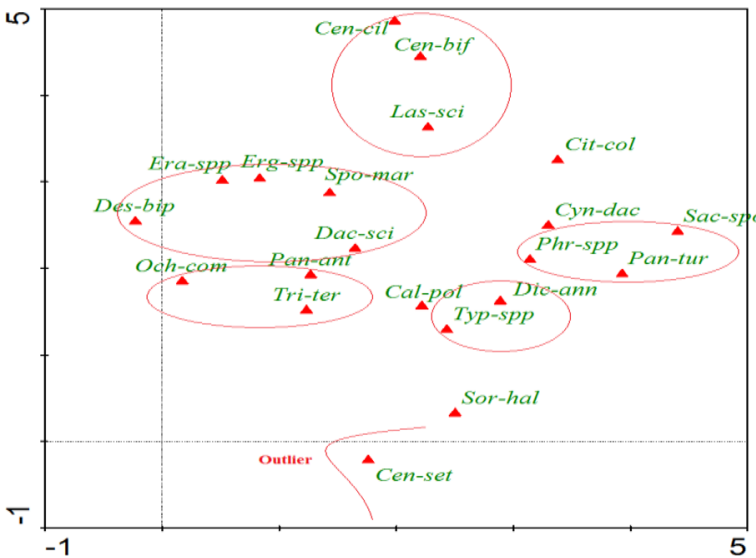

Fig. 3 DCA scatter plot

dendogram. Similarly, Phragmites species, Panicum turgidum and Saccharum spontaneum were shown as associated species as revealed by the community II in Fig. 1.

Results of analytical test of soil samples showed the varied concentrations of micronutrients (zinc, copper, ferrous and manganese) and macronutrients ( $\mathrm{P}$ and $\mathrm{K}$ ) up to greater levels along with other parameters, i.e., $\mathrm{pH}, \mathrm{EC}$, moisture and organic matter. The range of analyzed $\mathrm{pH}$ and EC of soil samples was 7.4-7.8 and 0.8-1.4, respectively, in the soil samples. $0.9-1.8 \%$ organic content was found along with $20-41 \%$ moisture.

Figure 4 shows the T-value biplot which indicated the positive and negative correlations of all identified species with all analyzed edaphic factors. Arrowheads and length show the response of species to the selected environmental variable. Likewise, in Fig. 4 results of direct ordination technique showed the influence on the growth of $O$. compressa, C. dactylon, S. spontaneum, P. turgidum, P. species, $D$. bipinnata, C. biflorus, C. ciliaris and E. species by macronutrients (potassium) and micronutrients (copper and zinc). All other identified species had no significant effect of $\mathrm{Fe}^{+3}$ and $\mathrm{Mn}^{+2}$ on growth and abundance.

Results showed the assumptions about the variables and predictors in Figs. 5 and 6 . The assumed relation between stochastic and systematic components indicated the Gaussian reference distribution of response variable on the scale of predictor. It was found that $D$. bipinnata grown over the wide range of $\mathrm{pH}, \mathrm{EC}$, potassium and phosphorus. Most abundant species was Cynodon dactylon which showed higher growth, but did not revealed the equal distribution over the found range of physiochemical properties of soil. Likewise, with increasing $\mathrm{pH}$, growth of $C$. dactylon was also increasing. Similarly, abundance of C. dactylon was found at higher concentration of potassium. Different species showed different responses at different concentrations of micronutrients $(\mathrm{Zn}, \mathrm{Mg}$, Fe and
Cu). Concentration range of copper (1.28-1.66 ppm) in study area soil was found most suitable for the growth of all identified species shown in Fig. 6a. Comparatively, the determined range of iron concentration (3.3-4.8 ppm) in soil depicted that the lower concentration supports the higher growth of S. spontaneum. C. setigerus showed the higher growth at higher concentration of manganese, and C. dactylon showed the abundance at both the lower and higher manganese concentrations (Fig. 6c). D. bipinnata showed equal distribution at 3.1-4.6 ppm. D. bipinnata was most abundant and dispersed species at the zinc concentration ranging from 0.5 to $0.9 \mathrm{ppm}$ (Fig. $6 \mathrm{~d}$ ). At the same concentration range, the growth of $S$. spontaneum was also found well distributed in the study area.

Different ecologists have employed the technique of multivariate for the analysis of vegetation to describe the species frequency or abundance on the basis and response to variable environmental gradients [20]. A study was carried on plant classification using TWINSPAN methods and the 22 species belonging to 10 families were identified. Researchers also indicated the significant role of microand macronutrients in species growth response toward the environment [21].

Similar study on the same method was conducted in Ayubia National Park, which imparts an important role in conservation and protection of native flora. In this study total 59 species belong to 32 families were classified and two communities were identified comprised of Herd nepalensis, Plantago major and Rumex nepalensis [22].

Results revealed that the $C$. dactylon and D. bipinnata were found as the most abundant species in the Tharparker and considered as environmentally friendly species. It is also used as low-cost feedstock for animals.

One reason for $C$. dactylon abundance is could be the long-distance dispersal of its pollen by the wind in large amount [23]. Besides, this species also has unique morphology because it only requires $13 \mathrm{~h}$ to grow at 6.3-6.8 optimum $\mathrm{pH}$ of soil. So another factor for its abundance is the prevailing condition and adaptive nature of $C$. dactylon in a wide range of climates and did not show the dormancy in any season $[20,24]$. Soil texture found in the study area was sandy and sandy loam. Soil texture is a very important parameter which has a function to hold water and responsible for the aeration and also plays vital role in soil fertility [25].

Results showed the satisfactory concentration of organic matter (1.62\%) which indicated the favorable condition for plant growth. Different studies have highlighted the role of organic matter in growth and abundance of plants [20, 26-28]. pH of soil sample was found alkaline (7.6-7.8). All nutrients in soil are easily available to plants at $7-7.5 \mathrm{pH}$, but at above $\mathrm{pH}$ range micronutrients are not available easily to the plants. The negative relationship 

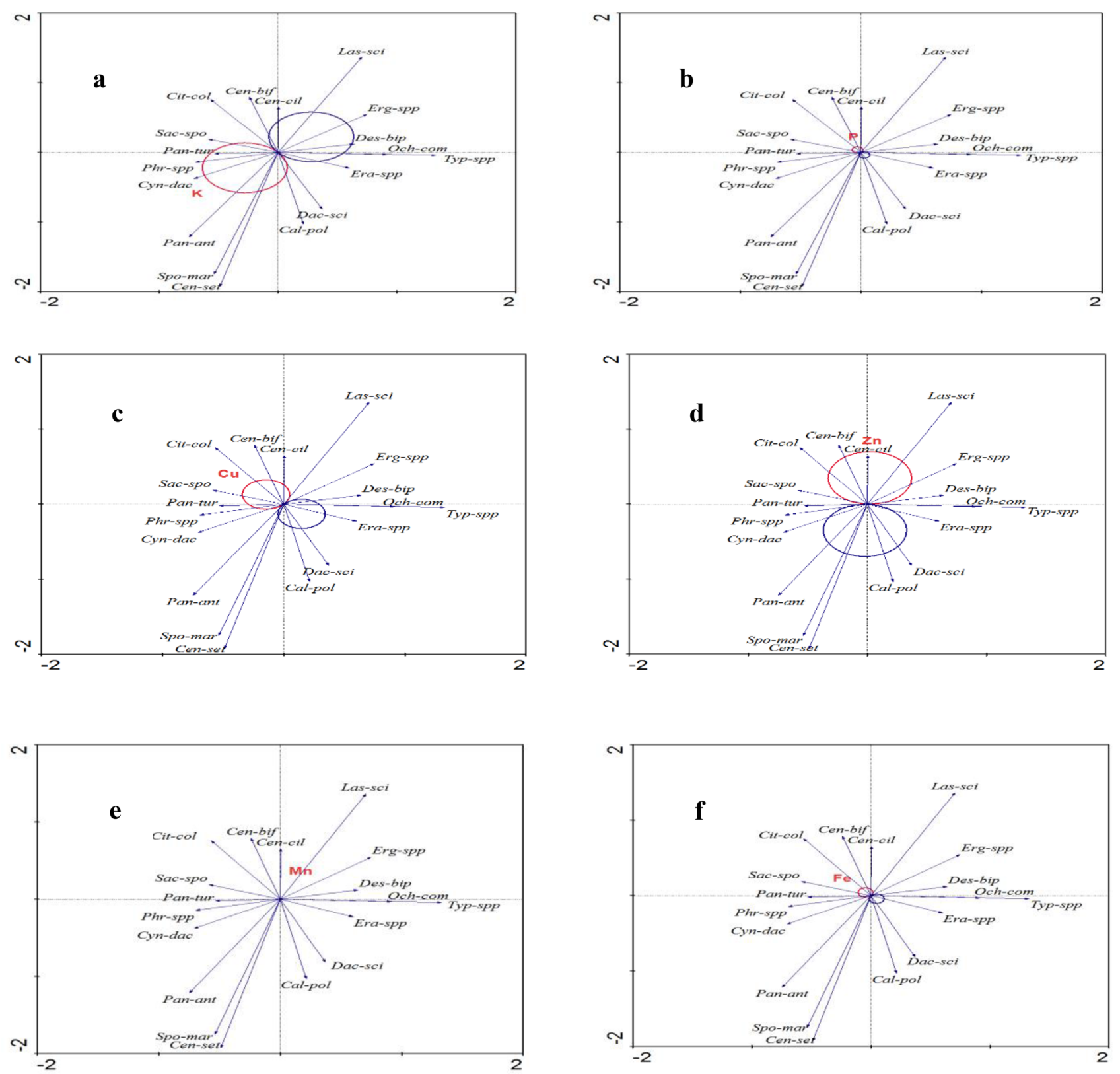

Fig. 4 T-value biplot of macronutrients and micronutrients

between $\mathrm{pH}$ and EC was studied by Regassa in the year 2005 [29].

According to Regassa, lesser nutrients will be available in soil to plants if the soil has higher $\mathrm{pH}$ and lower EC. Beneficial microbes are available at lesser soil $\mathrm{pH}$. Likewise, nitrogen fixing bacteria are present at $6-8$ soil $\mathrm{pH}$. By using direct ordination techniques like CCA, relative position of species does not influence by making clusters and accurate response can be achieved by showing abundance [30, 31]. GAM as a direct gradient technique is proved as the best modeling technique to show the plant response toward environmental gradients. The present study revealed that
Cynodon Dactylon was most resistant species over the prevailing condition of soil $\mathrm{pH}, \mathrm{EC}$, potassium, phosphorus, zinc, iron, copper and manganese concentration ranges in Tharparker. Similarly, the study of Bashir et al. [14] showed the potential of Cynodon Dactylon on different recorded concentrations of edaphic factors. 

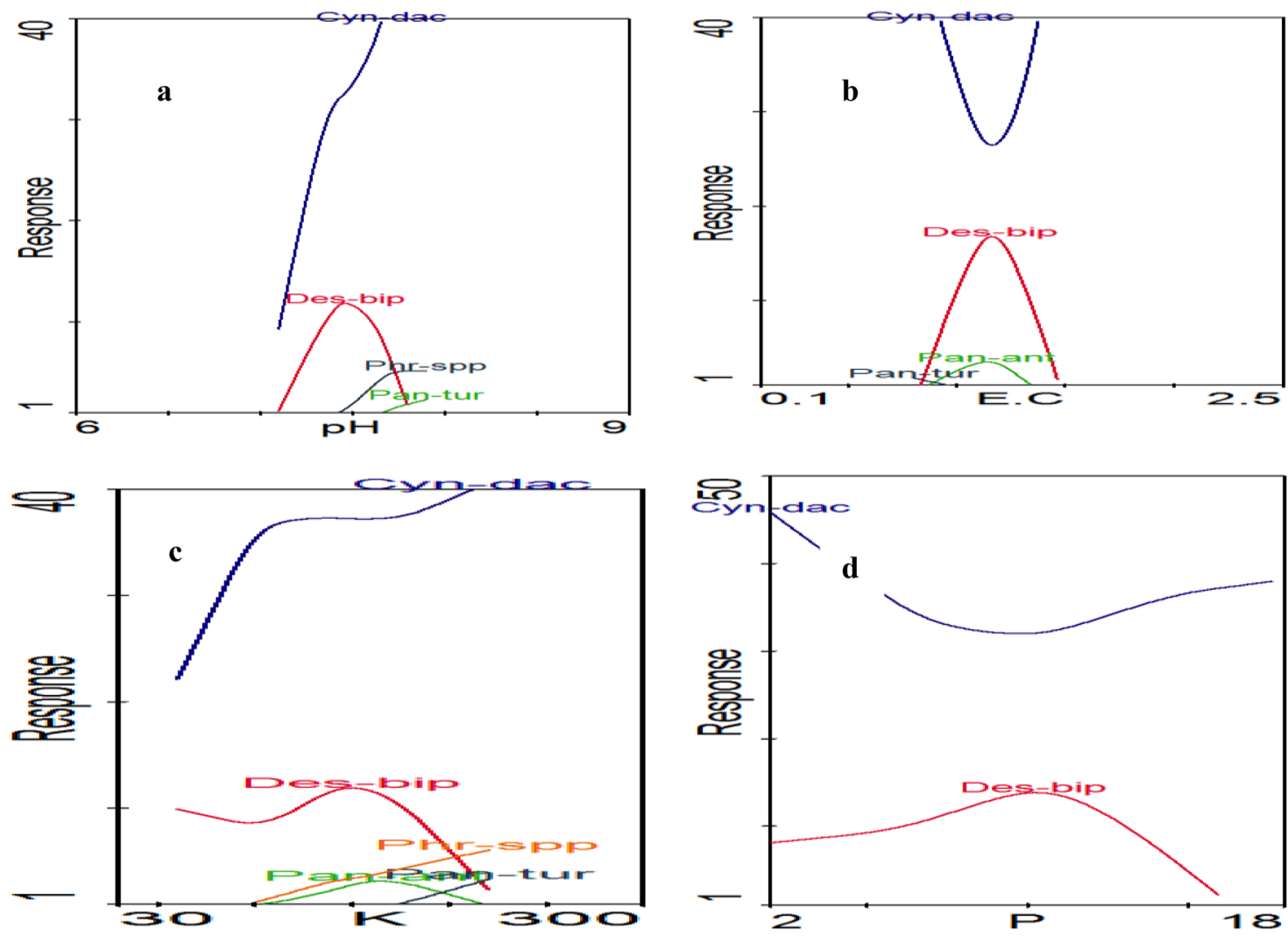

Fig. 5 Growth response of species against concentration range of $\mathrm{pH}, \mathrm{EC}$ and macronutrients
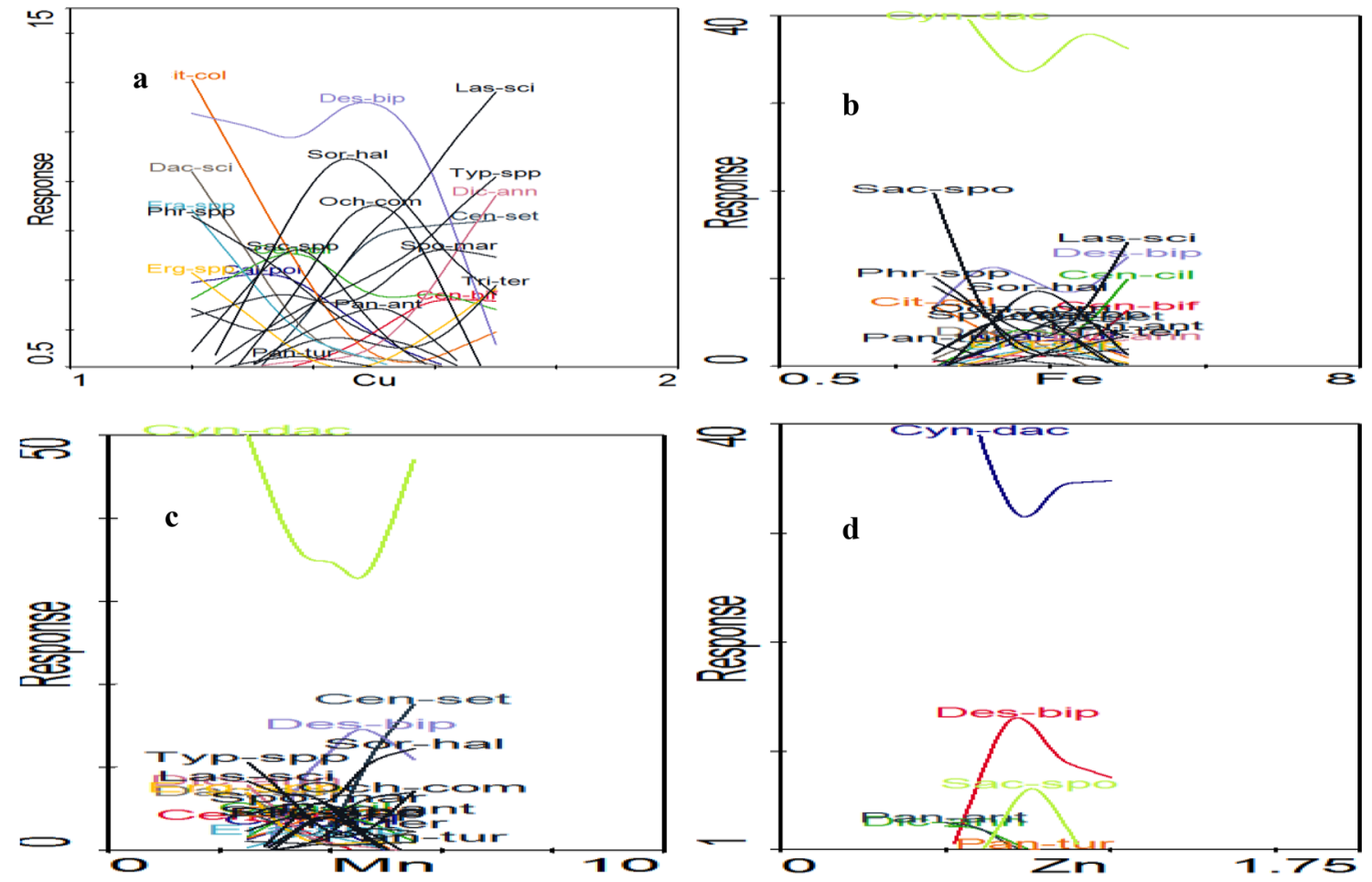

Fig. 6 Growth response of species against concentration range of micronutrients 


\section{Conclusions}

The present study was conducted to classify and assess the herbaceous flora in Tharparker by employing TWINSPAN, DCA and CCA. Different responses of every species toward environmental variable were recorded and developed visually by scaling models. Model represented the greater abundance and regular distribution of $C$. dactylon at a wide range of analyzed soil parameters. The analyzed concentration of micronutrients and macronutrients was found effective in the growth of every species; in particular, $\mathrm{pH}$, zinc and moisture have greater influence on species frequency and abundance. This study is a model study to set a step forward for detailed study about the herbaceous vegetation in Tharparker, because of its importance as a protected area. It is needed to accomplish and monitor the natural resources. This will also help in making decision to manage the present condition and adopt better conservation practices for herbaceous flora that account $60 \%$ of Tharparker vegetation.

Acknowledgement The authors are thankful to the Punjab Higher Education Commission for Postdoc fellowship funding.

\section{Compliance with ethical standards}

Conflict of interest The authors have no conflict of interest. The authors did not cause any damages and harm to the protected area. It is open to all for research in Pakistan.

\section{References}

1. Guisan A, Zimmermann NE (2000) Predictive habitat distribution models in ecology. Ecol Mod 135:147-186

2. McCune B, Mefford MJ (2011) PC-ORD. Multivariate analysis of ecological Data. Oregon, USA

3. Khaznadar M, Vogiatzakis IN, Griffiths GH (2009) Land degradation and vegetation distribution in Chott El Beida wetland, Algeria. J Arid Environ 73(3):369-377

4. Khan M, Hussain F, Musharaf S (2014) Ordination and classification of vegetation in semi arid area of Pakistan. Glob J Sci Fron Res 14(2):11-19

5. Urooj R (2017) Ordinal classification of vegetation: multivariate analysis. LAP Lambert Academic Publishing, Saarbrücken

6. Ahmad SS, Yasmin T (2011) Vegetation classification along Hanna Lake, Baluchistan using ordination techniques. Pak J Bot 43(2):863-872

7. Saand MA, Mirbahar AA, Khaskheli NK, Ansari KA, Khaskheli SA, Jamro MMR, Sirohi MH (2019) Post monsoon floristic inventory of Nagarparkar, District Tharparker, Sindh, Pakistan. Pure Appl Biol 8(1):968-976

8. Kent M, Coker P (1995) Vegetation description and analysis. Belhaven Press, London, pp 101-103

9. Hill MO (1979) Decorana a fortran program for detrended correspondence analysis and reciprocal averaging. Ecology and systematics. Cornell University, New York, p 52
10. Ahmad SS, Nawaz M, Wahid A, Malik B, Urooj R (2014) Scaling of multivariate ground flora data of Gatwala Forest Park (GFP), Faisalabad Pakistan. World Appl Sci J 29(12):1492-1496

11. Ahmad SS, Erum S, Khan SM, Nawaz M (2014) An appraisal of ecological distribution of herbaceous flora at Changa Manga Park Lahore, Pakistan. Pak J Bot 46(1):19-25

12. Urooj R, Ahmad SS, Ahmad MN, Ahmad H, Nawaz M (2016) Ordination study of vegetation analysis around wetland area: a case study of Mangla Dam, Azad Kashmir, Pakistan. Pak J Bot 48(1):115-119

13. Jia X, Chenand J, Wan $\mathrm{H}$ (2007) Application present situation of DCA, CCA, and DCCA ordination of grassland vegetation communities in China. Chin Agri Sci Bull 23(12):391-395

14. Bashir H, Ahmad SS, Urooj R, Nawaz M (2017) Modeling some plant species distribution against environmental gradients using multivariate regression models. Kuwait J Sci 44(4):119-128

15. Nathan MV, Gelderman R (2012) Recommended chemical soil test procedure. http://www.agvise.com/wpcontent/uploa ds/2014/06/Recommended-chemical-soil-testprocedures-2012. pdf. Accessed 30 Dec 2017

16. Ehi-Eromosel CO, Adaramodu AA, Anake WU, Ajanaku CO, Edobor-Osoh A (2012) Comparison of three methods of digestion for trace metal analysis in surface dust collected from an E-waste recycling site. Nat Sci 10(10):42-47

17. McCullagh P, Nelder JA (2019) Generalized linear models. Routledge, New York

18. Gelman A, Goodrich B, Gabry J, Vehtari A (2019) R-squared for Bayesian regression models. Am Stat 1(1):1-3

19. Spiegel E, Kneib T, Otto-Sobotka F (2019) Generalized additive models with flexible response functions. Stat Comp 29(1):123-138

20. Urooj R, Ahmad SS, Ahmad MN, Khan S (2015) Ordinal classification of vegetation along Mangla Dam, Mirpur, AJK. Pak J Bot 47(4):1423-1428

21. Frouz J, Prach K, Pizl V, Hanel L, Stary J, Tajovsky K, Materna J, Balik V, Kalcik J, Ehounkova K (2008) Interactions between soil development, vegetation and soil fauna during spontaneous succession in post mining sites. Eur J Soil Biol 44(1):109-121

22. Ahmad SS, Ann QU (2011) Exploring the vegetation dynamics and community assemblage in Ayubia National Park, Rawalpindi, Pakistan, using CCA. Biodivers J 2(3):115-120

23. Small $E$, Antle $T$ (2003) A preliminary study of pollen dispersal in Cannabis sativa in relation to wind direction. J Ind Hemp $8(2): 37-50$

24. Ahmad SS, Murtaza R, Shabir R, Ahmed MN, Shah TA (2014) Environmental diversification and spatial variations in Riparian vegetation: a case study of Korang River, Islamabad. Pak J Bot 46(4):1203-1210

25. Donahue RL, Miller RW, Shickluna JC (1983) Soil: an introduction to soil and plant growth, 5th edn. Prentice-Hall of India Private Limited, New Dehli

26. Leszczyńska D, Kwiatkowska-Malina J (2011) Effect of organic matter from various sources on yield and quality of plant on soils contaminated with heavy metals. Ecol Chem Eng 18(4):501-507

27. Benedetti MF, Van Riemsdijk WH, Koopal LK, Kinniburgh DG, Goody DC, Milne CJ (1996) Metal ion binding by natural organic matter: from the model to the field. Geochim Cosmochim Acta 60(14):2503-2513

28. Yin Y, Impellitteri CA, You SJ, Allen HE (2002) The importance of organic matter distribution and extract soil: solution ratio on desorption of heavy metals from soils. Sci Total Environ 287(1):107-119

29. Regassa T (2005) An ecological study of vegetation around Lake Abijata. MSc thesis, Addis Ababa University School of Graduate studies. http://etd.aau.edu.et/bitstream/123456789/444/2/ TOLCHA\%20REGASSA.pdf. Accessed 5 Dec 2013 
30. Mohler CL (1981) Effects of sample distribution along gradients on eigenvector ordination. Vegetatio 45(3):141-145

31. Zhang L, Mi X, Shao H, Ma K (2011) Strong plant-soil associations in a heterogeneous subtropical broad-leaved forest. Plant Soil $347(1): 211-220$
Publisher's Note Springer Nature remains neutral with regard to jurisdictional claims in published maps and institutional affiliations. 